IMPORTANT: When citing this article, please refer to the print-version:

Honnefelder, Ludger / Runggaldier, Edmund / Schick, Benedikt (eds.)

Unity and Time as Problems in Metaphysics. Berlin/New York: 2009, 237-252.

\title{
NATURAL INDIVIDUALS AND INTRINSIC PROPERTIES
}

\author{
GODEHARD BRÜNTRUP
}

\begin{abstract}
In the world there are concrete particulars that exhibit the kind of substantial unity that allows them to be called substances or "natural individuals", as opposed to artifacts or mere conglomerates. Persons, animals, and possibly the most fundamental physical simples are all natural individuals. What gives these entities the ontological status of a substantial unity? Arguments from the philosophy of mind and arguments from general metaphysics show that physical properties alone cannot account for substantial unity. The ultimate intrinsic properties of natural individuals resemble phenomenal mental properties rather than any other kind of known properties. Pan(proto-)psychism is thus supported by systematically related arguments from different areas of philosophical inquiry. A certain amount of skepticism regarding the full nature of absolutely intrinsic properties is nevertheless well-advised.
\end{abstract}

\section{Introduction}

In recent analytic philosophy, a substance has mainly been conceived as that which endures through time. The debate between endurantists and perdurantists became thus the centerpiece of many discussions. There is, however, another historically quite influential aspect of substantiality. A substance is something that exists (or possibly can exist) by itself. Substances are ontologically selfsufficient; they do have an intrinsic nature that is not bestowed on them by entering certain accidental relations. This notion of a substance would encompass also very short-lived and eventlike entities. If they are part of the ontological array of concrete entities, they are also substances in this sense. Because the notion of a substance is heavily loaded with preconceptions, I choose to call them "natural individuals." They are "natural" because they are to be distinguished from artifacts like computers or TV sets. They are individuals because they are to be distinguished from mere conglomerates, like a pile of stones or a cloud formation. I wish to argue that there is a substantive theoretical link between the discussion about the intrinsic natures of natural individuals and some developments in the philosophy of mind.

In recent philosophy of mind, the discussion of the "hard problem of consciousness" has resulted in a widespread acceptance of the thesis that the qualitative mental properties of phenomenal experience cannot be fully reduced to physical properties. It is the intrinsic qualitative aspect of the mental that cannot be captured by the causal and functional concepts of the physical sciences. Because of their intrinsic nature, qualitative mental states cannot be captured by scientific analysis. The properties that science finds are all dispositional. Dispositions require a categorical (nondispositional) basis on which they supervene. For present purposes I will mean by "intrinsic properties" those properties that a thing has in itself, independently of its relations to other things: the properties it could have even if it were the only thing in the universe. The mental properties of the Cartesian thinking thing are intrinsic in this sense. It can be conceived that all of its mental states could exist even without a material external world. The richness of its intrinsic properties is in principle independent of external relations (maybe with the exception of God). Thus, in contemporary philosophy of mind, functionalism has been criticized as capturing only the relational 
IMPORTANT: When citing this article, please refer to the print-version:

\section{Honnefelder, Ludger / Runggaldier, Edmund / Schick, Benedikt (eds.) Unity and Time as Problems in Metaphysics. Berlin/New York: 2009, 237-252.}

aspects of mind, and missing the intrinsic, qualitative mental properties. Can physical properties be intrinsic in this sense? That is a difficult question. Mass is by some considered to be an intrinsic property. But then, having a mass of $\mathrm{m}$ is a property such that something that has that property will play a certain functional role defined by a relation of force and acceleration: $\mathrm{m}=\mathrm{F} / \mathrm{a}$. What about rest mass? It is a consequence of general relativity that only an isolated system would have a coordinate-independent mass. Since a non-isolated system is constantly exchanging energymomentum with its environment, the mass at a certain point in time would depend on the simultaneity determinations of the observer. In quantum mechanics mass is ultimately explained by the Higgs mechanism, which clearly is a functional concept. It seems that, if only we dig deep enough, even physical concepts that looked prima facie like non-relational intrinsic properties, turn out to be defined relationally. It is thus reasonable to ask: What is the intrinsic categorical nature of those entities that are relationally defined by physics?

A similar question was asked in early modern philosophy about the intelligibility of the Cartesian notion of a material substance as an extended thing. The main argument here is that extension is a relation which cannot on its own constitute a substance. It presupposes some intrinsic nature of the relata, the terms of the relation. A system of spatial relationships is too incomplete to constitute areal concrete entity. More recently, Max Newman (Newman 1928) argued against Russell's view that we know only the structural features of the world. He claimed that, unless we take into account the intrinsic features of the relata, there will be too many relations. The existence of a set of relations is trivially true of a set of objects unless the relata have some qualitative intrinsic properties. Mere relations are just sets of ordered sequences of entities. And there are too many of them for any given number of objects, unless the intrinsic nature of those objects determines a specific relational structure. Newman reads this as a reductio against relationalism, claiming that a relationalist view of the world lacks any substantive ontological content except for a trivial claim about the cardinality of individuals in this world. One can also read this idea more in the line of Putnam's "model-theoretic argument" (Putnam 1980). There are too many ontological interpretations (models) of our theories. Our scientific descriptions of the world are unable to single out the intended model, i.e., the real world. Similarly, if objects are mere nodes in a relational graph with no intrinsic nature, then too many relational graphs are possible. Since science deals only with the relational structure, not the intrinsic natures, we can never know the one true story about the world in a metaphysical-realist way. We have too many "truths."

It seems that what is missing in the merely relational definition of a physical entity is some intrinsic qualitative aspect that grounds and determines the relations. Possible candidates for such grounding intrinsic properties are (proto-)mental or (proto-)experiential properties. If that is the case, then a realistic physicalism or naturalism entails panpsychism, as has been recently argued by authors like David Chalmers, Galen Strawson and Gregg Rosenberg.

\section{Intrinsic properties and the philosophy of mind}

Many arguments have been advanced to show that facts about qualia are not implied by physical facts. The most famous being the one about Mary the perfect neuroscientist who has never seen a color. Initially, I will focus here on David Chalmers' famous "zombie argument" because it helps to clearly indicate where in the logical structure of the debate the physicalist is forced to draw panpsychist conclusions. The general form of the argument is this (Chalmers 2002, 249): Let P be the conjunction of all micro-physical truths about the universe, and let $\mathrm{Q}$ be an arbitrary phenomenal truth about the universe. 
IMPORTANT: When citing this article, please refer to the print-version:

\section{Honnefelder, Ludger / Runggaldier, Edmund / Schick, Benedikt (eds.) Unity and Time as Problems in Metaphysics. Berlin/New York: 2009, 237-252.}

(1) $P \& \sim Q$ is conceivable.

(2) If $P \& \sim Q$ is conceivable, $P \& \sim Q$ is metaphysically possible.

(3) If $P \& \sim Q$ is metaphysically possible, materialism is false.

(4) Materialism is false.

But, says the standard scientific essentialist (type-B materialist), $P \& \sim Q$ is only conceivable but not metaphysically possible. The mistake, according to the type-B materialist, is that we are working with primary intensions when dealing with epistemic possibility (conceivability), and with secondary intensions when dealing with metaphysical possibility. In the first case, we consider a world as actual; in the latter case we consider a world as counterfactual (how things might have been but are not). If we consider Putnam's XYZ-world as actual, then "water is not $\mathrm{H}_{2} \mathrm{O}$ " is true. This is an instance of an epistemic possibility. If we rigidly hold the meaning of "water" fixed by the actual world and counterfactually consider the XYZ-world, then "water is not $\mathrm{H}_{2} \mathrm{O}$ " turns out to be false. Then "water is $\mathrm{H}_{2} \mathrm{O}$ " expresses a Kripkean necessary truth. Let us call possibility associated with primary intensions "l-possibility," and possibility associated with secondary intensions "2-possibility." In order for Chalmers' argument to meet the challenge of type Bmaterialism, it should rather look like this (Chalmers 2009):

(1) $P \& \sim Q$ is conceivable.

(2) If $P \& \sim Q$ is conceivable, $P \& \sim Q$ is 1-possible.

(3) If $P \& \sim Q$ is 1-possible, $P \& \sim Q$ is 2-possible.

(4) If $P \& \sim Q$ is 2-possible, materialism is false.

(5) Materialism is false.

Here, the truth of (3) requires that both $\mathrm{P}$ and $\mathrm{Q}$ have primary and secondary intensions that coincide. In the case of $\mathrm{Q}$, this seems unproblematic. If something feels like pain, it is pain. If something feels like consciousness, it is consciousness. In the case of $\mathrm{P}$, however, the issue becomes much more problematic. Physical properties are functionally defined. We can say that the primary intension of "mass" picks out whatever plays the mass role in a given world. We can also say that the secondary intension of "mass" is tied to the property playing that role in our world in such a way that in a world where something else plays the mass role, this role filler is not mass. Premise (3) can be rejected on these grounds. But what does that mean? In that case there would be possible worlds that verify the structural-relational description of our world in physical terms without being an exact duplicate of our world. The physical structure of those other worlds would be indistinguishable from our world, but the intrinsic natures carrying those relations would be different. The most interesting case would be worlds verifying $P \& \sim Q$. This leads to an interesting metaphysical picture: the relational-structural properties of physics in our world do not necessitate the Q-properties (phenomenal properties), the Q-properties do not supervene logically on the relational-structural properties. However, the relational-structural properties of physics together with additional intrinsic properties necessitate the emergence of phenomenal consciousness. This metaphysical picture has been eloquently expressed by Astronomer Sir Arthur Eddington in his work Space, Time, and Gravitation: "Physics is the knowledge of structural form, and not knowledge of content. All through the physical world runs that unknown content, which must surely be the stuff of our consciousness" (Eddington 1920, 200). Russell's "neutral monism" was based on similar intuitions: "As regards the world in general, both physical and mental, everything we know of its intrinsic character is derived from the mental side, and almost everything we know of its 
IMPORTANT: When citing this article, please refer to the print-version:

\section{Honnefelder, Ludger / Runggaldier, Edmund / Schick, Benedikt (eds.) Unity and Time as Problems in Metaphysics. Berlin/New York: 2009, 237-252.}

causal laws is derived from the physical side" (Russell 1927,402). The structure of Chalmers' argument thus comes finally down to this:

(1) $P \& \sim Q$ is conceivable.

(2) IfP $\& \sim Q$ is conceivable, then $P \& \sim Q$ is 1-possible.

(3) If $P \& \sim Q$ is 1-possible, then $P \& \sim Q$ is 2-possible or Russellian monism is true.

(4) If $P \& \sim Q$ is 2-possible, materialism is false.

(5) Materialism is false or Russellian monism is true.

In the end, Chalmers thinks that traditional physicalism fails because he rejects the idea of a brute and inexplicable emergence of the mental from the physical. Only if there are (proto-)mental properties (intrinsic), nomologically connected to the physical properties (relational) by irreducible emergence laws, can the emergence of consciousness be necessitated in such a way that is no longer mysterious. Galen Strawson has in recent years developed a metaphysical theory based on a similar intuition. He calls it "realistic monism" or "real physicalism" (Strawson 2006). It is based on a venerable argument for panpsychism, the "genetic argument." It rests on a claim about the intelligibility of radical inter-attribute emergence, as opposed to weaker intra-attribute emergence. It mirrors the traditional distinction between a strong inter-actionist substance dualism and a weaker intra-actionist dual-aspect theory or property dualism. In his paper, "Panpsychism" Thomas Nagel had argued that uniform psycho-physical correlations could not account for the emergence of mental properties from the physical components of a system: "Instead, intrinsic properties of the components must be discovered from which the mental properties of the system follow necessarily. This may be unattainable, but if mental phenomena have a causal explanation such properties must exist, and they will not be physical" (Nagel 1979, 187). Emergence cannot be brute in the sense of there being nothing in the emergence base in virtue of which the emergent phenomenon emerges: ex nihilo nihil fit. Nothing can give what it does not possess. In order to make sense of the emergence of consciousness, the evolution of the phenomenal mind must be smooth. Consciousness in some form must be present "at the very origin of things" (James 1890, 149). Inter-attribute emergence is to be avoided. Otherwise even a Cartesian soul could mysteriously emerge from a Cartesian physical body. One might as well try to "imagine" the emergence of a concrete physical object from a configuration of abstract mathematical objects. If such inter-attribute emergence is considered intelligible, then one will inevitably end up with a radical Humean view of causal powers in which "any thing may produce any thing" (Treatise, III, xv), and any reasonable prospect for a substantive metaphysical account of the mind-body relation will have vanished. If emergence is construed as an intra-attribute relation, however, then one has to give up the standard physicalist principle that there are no (proto-)mental properties at the ontological base levels. Strawson calls this dogma of contemporary physicalism the "NE principle": "physical stuff is, in itself, in its fundamental nature, something wholly and utterly non-experiential" (Strawson 2006, 11). The intuition that a system that is only structurally defined cannot give rise to qualitative experience is more than just an epistemic problem of cognitive upward opacity that might be overcome by more empirical research; it is a deep metaphysical puzzle. One of the best ways to present this lack of analysis is the "argument from cellular automata" by Gregg Rosenberg (Rosenberg 2004, 14-30). Cellular automata are artificial digital worlds consisting of basic particulars called "cells" in an abstract space. These cells have relational properties connecting them to other cells. Computer modelers define various worlds by giving the cells different properties and then study their dynamics through consecutive computational steps. This is usually done by defining rules that determine which 
IMPORTANT: When citing this article, please refer to the print-version:

\section{Honnefelder, Ludger / Runggaldier, Edmund / Schick, Benedikt (eds.) Unity and Time as Problems in Metaphysics. Berlin/New York: 2009, 237-252.}

properties a cell will have at a given time as a function of which properties the neighboring cells had at an immediately preceding time. In simple versions of cellular automata the basic particulars have only simple properties like "on" and "off." One can build on these humble beginnings and construct more complicated cellular automata that may ultimately mimic physical properties like spin, charge or mass. The fascinating fact is that despite its rather simple physics the cellular automaton is enormously versatile, in fact a universal Turing machine. Very quickly individual cells join together to build more and more complex structures and patterns that are sustained over many steps of computation. The machine seemingly produces endurants (stable relational patterns) which arise out of a sequence of event-like occurrents (discrete computational states of the system). Quickly these patterns become quite sophisticated, featuring a kind of non-trivial self-replication that is functionally similar to certain structures of living beings, like DNA. For this reason cellular automata are sometimes called "life worlds." The basic facts of cellular automata, the distribution of properties over the grid of cells, necessitate the higher-level structural facts about stable emerging patterns. There is no mysterious inter-attribute emergence involved, even though the emerging patterns exhibit new properties that cannot be attributed to individual cells. Everything happens within one strictly delineated ontological scheme. Standard physicalism assumes that our world is an extremely complex cellular automaton. Thus the following problem arises:

(1) The fundamental facts of cellular automata are defined entirely by the dynamic relations of the cells.

(2) Facts of phenomenal consciousness are intrinsic qualitative facts, which cannot be entirely defined by the dynamic relations in which they enter.

(3) Facts about dynamic relations do not entail (a priori or a posteriori) intrinsic qualitative facts about phenomenal experience.

(4) Thus, the intrinsic qualitative facts about phenomenal experience are not entailed in the facts about cellular automata.

The question is then: if our world is a cellular automaton, how does the phenomenal mind emerge? This is exactly the problem raised by the "genetic argument" for panpsychism. To avoid this notoriously hard problem, one can resort to the denial of the existence of phenomenal experience and become an eliminativist about the phenomenal mind. Strawson is quite outspoken about this strategy: "This particular denial is the strangest thing that has ever happened in the history of human thought, not just the whole history of philosophy. It falls, unfortunately, to philosophy, not religion, to reveal the deepest woo-woo of the human mind" (Strawson 2006, 6). It seems more reasonable to assume that the functional-relational picture of the world assumed in the model of cellular automata is somehow incomplete. This was indeed Russell's intuition. Maybe we are missing something about the intrinsic nature of the physical world in virtue of which (plus the relevant laws) the emergence of conscious mind can be explained. This is, of course, just a conjecture, but it is certainly a possibility that knowledge of the intrinsic properties of matter would help to overcome the puzzle of inter-attribute emergence. In Russell's words: "The physical world is only known as regards certain abstract features of its space-time structure - features which, because of their abstractness, do not suffice to show whether the world is, or is not, different in intrinsic character from the world of mind" (Russell 1948, 240). To use Whitehead's term, the modern notion of matter presents us with "vacuous" entities whose intrinsic nature is unknown. Inspired by Humean arguments, Peter Unger has recently presented a visually compelling picture of this problem. Let us define two worlds in purely structural terms, not assuming any intrinsic qualitative properties. The 
IMPORTANT: When citing this article, please refer to the print-version:

\section{Honnefelder, Ludger / Runggaldier, Edmund / Schick, Benedikt (eds.) Unity and Time as Problems in Metaphysics. Berlin/New York: 2009, 237-252.}

first world is a classical Newtonian world of particles moving about in empty space according to the laws of physics. Call this the "particulate world." In the second world there is a continuous material plenum (a continuous field of matter) in which there are little perfectly empty spaces, or absolute vacua, or simply "bubbles." Call this the "plenumate world." Now let us assume that the two worlds stand in an isomorphic relation in such a way that for each particle in the particulate world there is a corresponding bubble in the plenumate world (in the same location, governed by the same laws). It is Unger's contention that these two worlds are functionally equivalent (Unger 2006, 21-31). A functional-relational description would be unable to capture the differences between these two worlds. To put it in different terms: If we were to construct cellular automata to model these worlds, only one would be needed to model both. Maybe this picture relies too much on visual imaginability, but it nevertheless captures the intuition that the abstractness of the relational structure really "abstracts away" from something that needs to be added to complete the metaphysical picture. The genetic argument for panpsychism claims that we have good reason to believe that this "something," which is being abstracted away from, better be something (proto-)mental, since otherwise the emergence of the phenomenal mind remains mysterious. But the problem of emergence is not the only reason that could motivate a critique of the functionalrelational picture. A similar line of argument was developed long before contemporary philosophy of mind. Modern philosophy was quite critical of Descartes' notion of a material substance, a notion that still governs the scientific world-view to this day.

\section{Intrinsic properties and the metaphysics of natural individuals}

The metaphysical question is whether something as abstract as a formal system of spatio-temporal relations is sufficient to account for the concrete substantiality or thinghood of a natural individual. A structure must be a structure of something. Robert Adams recently presented a line of thought similar to Unger's. He claims that we cannot imagine a shape without some chromatic property. The formal entity needs a "filling." And from there he goes on to argue: "We may conjecture that the reality of a substance must include something intrinsic and qualitative over and above any formal or structural features it may possess" (Adams 2007, 40). But early modern thought had expelled all qualitative, non-structural qualities from material bodies and had placed them entirely inside the mind. A view that Whitehead has characterized brilliantly: "The poets are entirely mistaken. They should address their lyrics to themselves, and should turn them into odes of self-congratulation on the excellency of the human mind. Nature is a dull affair, soundless, scentless, colourless; merely the hurrying of material, endlessly, meaninglessly" (Whitehead 1925, 80). Assuming a "real physicalism" (in the sense of Strawson) we cannot take refuge in Cartesian dualism or mysterious emergence. Human persons are natural individuals and material objects. But if it is from the experiential qualities that human persons derive their positive non-formal content as substances, could we then not reasonably ask if humans are but one special case of natural individuals and that natural substances as such require such positive content. We would thus be siding with Whitehead in claiming that some sort of qualitative intrinsic content is constitutive of nature at large. A quick survey of some topics in early modern philosophy will prove helpful in exploring this issue.

In a brilliant piece of skeptical reasoning, Hume challenges the notion of a Cartesian material substance. He claims that upon the removal of sensible qualities from the rank of independent existences, we are merely reduced to primary qualities like figure, motion and cohesion. This process, instead of aiding in explaining the operations of external objects, utterly annihilates all these objects, resulting in the most extravagant skepticism concerning them. And he goes on: "If 
IMPORTANT: When citing this article, please refer to the print-version:

\section{Honnefelder, Ludger / Runggaldier, Edmund / Schick, Benedikt (eds.) Unity and Time as Problems in Metaphysics. Berlin/New York: 2009, 237-252.}

colours, sounds, tastes, and smells be merely perceptions, nothing we can conceive is possest of a real, continued, and independent existence; not even motion, extension and solidity, which are the primary qualities chiefly insisted on" (Hume 1739, IV, iv, 512f.).

Indeed, Descartes claims that spatial extension is the essence of corporeal substance, and nothing else contributes to it. For Descartes the very nature of a substance is determined by its attributes. He does not construe substances as mere substrata or bare this-ness. He argues that the distinction between the notion of a substance and its attributes is merely a distinction of reason not areal distinction: "For there is some difficulty in separating the notion of substance from the notions of thought or extension, which of course differ from substance only in the reason" (Principles 1.63). A material Cartesian substance is thus nothing but modes of extension, i.e., shape, size, and motion in space. The key question for our present purposes is whether or not this notion of a substance as mere extension is ultimately intelligible. What can it mean that there is no real distinction between body and spatial extension? It seems that there has to be something that is extended in space, and that something cannot again be just space. Here the problem with relationalism resurfaces again. In his critique of Descartes' notion of a material substance, Leibniz argues that extension can be analyzed in merely relational terms; but then the question about the intrinsic nature of the relata arises. In a letter to de Volder, Leibniz makes the point that extension cannot be conceived in itself. Extension for him, is not a primitive but an analyzable concept; it can be analyzed into plurality, continuity, and coexistence or the existence of parts at one and the same time. ${ }^{1}$ But parts of what? As Leibniz argues elsewhere, extension is just a continuous multiplicity of something that is spread out. The nature of the substance that is being spread out is not explicated by the concept of extension; on the contrary, it is ontologically prior to the repetitive multiplicity of extension (G IV, 467). Challenging Descartes, Leibniz claims that extension cannot be something absolute, it rather is something relative to what is being expanded: "... extensionem non esse absolutum, quoddam praedicatum, sed relativum ad id quod extenditur sive diffunditur" (G IV, 394). The key intuition here is again that extension, due to its formal-relational character, is too abstract to constitute a concrete individual substance in the same way that neither multitude nor number constitute a substance, unless we are ready to specify what it is that is repeated or numbered. Something ontologically prior must be assumed which is continued or diffused. Leibniz gives these intuitive examples: "whiteness in milk, color, ductility and weight in gold, and resistance in matter" (to de Volder, IV 1699, G II, 170). An "extended thing on its own" is impossible, it could not even be extended. The relational properties of substances must have an underlying foundation of intrinsic properties. Famously, Leibniz claimed that there is no denomination so extrinsic that it does not have something intrinsic as its foundation (to de Volder, IV 1702, G II, 240). If this is correct, then we need ultimate intrinsic properties that carry the entire net of functional-relational properties in the world. This intuition resurfaces in contemporary debates. In his paper "Pattern and Being", John Haugeland assumes the traditional view that a substance needs properties which it has regardless of anything else. He then considers the ontological status of the pieces in a chess game - say a rook or a pawn - and claims that their very nature is determined entirely by how they move about in the chess game in relation to other pieces. He then concludes:

"No rook is a substance .... Nothing about a rook is determinate, not even its 'rookness,' apart from

1 Leibniz to de Volder, IV 1699, G II, 169f. I owe this quote and some other helpful references to early modern philosophy to the unpublished manuscript "Physicalism and Absolutely Intrinsic Properties" by Derek Pereboom. It is available online at consciousness.anu.edu.au/papers/pereboom.doc.

Adams 2007 also provides some illuminating references to Leibniz, Hume, Locke and Kant.

A new English translation of the Leibniz - de Volder correspondence has been completed by Paul Lodge and will be published by Yale University Press (forthcoming 2011). 
IMPORTANT: When citing this article, please refer to the print-version:

\section{Honnefelder, Ludger / Runggaldier, Edmund / Schick, Benedikt (eds.) Unity and Time as Problems in Metaphysics. Berlin/New York: 2009, 237-252.}

its participation in a chess game" (Haugeland 1993, 63). The situation is even more complicated. The formal definition of a type in a chess game is circular. The nature of each type is completely determined by the set of allowable moves it makes within the game as a whole. The chess game as a whole, however, is defined by the interdependent set of types which play functional roles in it. Each part of the game presupposes the existence of the whole game, and the game presupposes the existence of its parts. Why isn't this circularity of chess categories vicious (cf. Rosenberg 2004, 234)? How can chess games actually and concretely exist? Rosenberg claims that there must be something distinct from the formal structure that actually grounds the game in concrete reality. In the case of a chess game we have physically distinct objects that serve as stand-ins or realizers of the relevant types, thus allowing for the existence of concrete tokens of those types. Of course, there is much more to consider here, like the concrete chess board or the physical position of the players in space. Without such "carriers" of the formal structure, the game would remain too incomplete and abstract to exist concretely. Rosenberg extends this thought to other, more complex, conceptual systems such as those constructed by scientific theories. They too are abstract and circularly defined, consider cellular automata in computer science again. Each cell is defined by its role in the entire system, and the entire system is defined by the cells. Cellular automata may exist as computational systems because there is something external to the formal system that realizes or carries it. The physical states of the hardware are the carriers of the cellular automata. Biology as an abstract conceptual system is carried by the mechanics of molecular biochemistry, psychology by the dynamical properties of the neural system, economics by the needs and desires of individuals. The crucial question is however: What carries the most basic physical level? Physics presents us a world of interdependently defined functional roles. Are there any properties that can give this circularly defined conceptual system a foothold in concrete reality? This is a puzzling question. Let us call it the "ultimate carrier problem." It is very similar to the question Leibniz raised with regard to Descartes' notion of matter. Not surprisingly, Rosenberg makes a similar move. He calls properties that are functionally defined within a system "intrinsic to a system" (Rosenberg 2004, 237). In order to avoid an infinite regress of ever more fine-grained systems, where each lower structure is serving as the carrier of the next higher one, a stopper is needed. Also, there are good scientific reasons to assume that nature has a lower size limit (planck size scale). Only a property that is intrinsic tout court and not relative to a system could bring this about and serve as an ultimate carrier. Are there properties that are not intrinsic to any system, but at least partly intrinsic to themselves? The only candidates we know of are phenomenal qualities. One cannot understand the nature of phenomenal qualities by knowledge of their contextual relations alone. This radical intrinsicness is the very nature of phenomenal qualia. Whatever grounds the structuralrelational properties of the world must have this radical intrinsicness. It might well be that our own consciousness is the closest analogue we get to this underlying reality.

A viable metaphysical alternative seems to be radical relationalism. Relationalism differs from functionalism exactly by getting rid of all realizers. According to relationalism, there is only the relational reality consisting of relations and nodes defined by their place in the overall relational system (cf. Dipert 1997). Nature is like a mathematical graph. There are no nonrelational properties. But since we know that our own intrinsic qualitative conscious phenomenal states exist, we already know that relationalism as a universal metaphysical doctrine cannot be true. There is more to the world than relations and point-like relata without intrinsic properties. Combining these two insights opens up a rationally well-grounded road to the acceptance of pan(proto-)psychism. This line of thought is often characterized as the "argument for panpsychism from intrinsic natures." It is at this point that the arguments for the irreducibility of qualia in the philosophy of mind and arguments for 
IMPORTANT: When citing this article, please refer to the print-version:

\section{Honnefelder, Ludger / Runggaldier, Edmund / Schick, Benedikt (eds.) Unity and Time as Problems in Metaphysics. Berlin/New York: 2009, 237-252.}

the intrinsic properties of natural individuals from general metaphysics start to point in the same direction.

This insight may be surprising to contemporary readers, but was well-known by many modern philosophers. For Kant it was obvious that the only absolutely intrinsic properties we can conceive of are taken from the mental realm. It is worthwhile to quote him at length: "It is quite otherwise with a substantia phaenomenon in space; its inner determinations are nothing but relations, and it itself is entirely made up of me re relations. We are acquainted with substance in space only through forces which are active in this and that space, either bringing other objects to it (attraction), or preventing them from penetrating into it (repulsion and impenetrability). We are not acquainted with any other properties constituting the concept of the substance which appears in space and which we call matter. As object of pure understanding, on the other hand, every substance must have inner determinations and powers which pertain to its inner reality. But what inner accidents can I entertain in thought, save only those which my inner sense presents to me? They must be something which is either itself a thinking or analogous to thinking" (CPR B321, transl. Norman Kemp Smith).

\section{The possibility of pan (proto-)psychism reconsidered}

By "analogous to thinking" Kant probably meant something like protomental properties that are in some relevant aspects similar to known mental properties but then also quite different from the highly developed mental properties of humans. But how could possibly all relational properties of material objects be grounded in intrinsic properties? And what does "grounding" mean in this context? If grounding means that the intrinsic properties are the constitution base of the relational extrinsic properties, then we have a metaphysical system in which certain fundamental entities with absolutely intrinsic properties constitute all the remainder of reality - a view, that Leibniz famously argued for in his Monadology. The key was to replace "mutual causal influence" with "mutual information" (Seager 2006, 4). The whole of physical space was constructed by giving each monad a spatial viewpoint from which space was constituted as experienced space. This seems too daring for most, and is considered by many as a position completely at odds with contemporary science. The latter claim may not be entirely accurate, however. Physicist David Bohm made a somewhat similar claim by introducing the quantum potential in order to provide an ontology for quantum mechanics. In the Bohmian interpretation, a single electron (say) passing to the lower slit in the two-slit experiment receives information by the quantum potential about the state of the entire system, including whether the upper slit is open or shut. It acts according to this information. Bohm talks about "active information", thus introducing mental representation and mental causation (causally efficacious mental content) at the most basic level of the universe (Bohm 1990). But it seems that electron is just mirroring the space around it, using the information presented in the quantum potential. Such mirroring would not be enough to actually constitute the spatial relations. This could only be the case if by being experienced in a certain way, spatial relations would come to exist in a certain way. This idea is clearly more related to another interpretation of quantum mechanics - the idea that reality becomes concrete and determined only relative to an experiencing observer. Here the experiencing observer becomes, at least partially, constitutive of reality. In his Mindful Universe Henry Stapp advances an interpretation of quantum mechanics according to which entities are ultimately bipolar - material and mental. The Schrödinger equation describes the deterministic and material aspect, the indeterministic collapse relates to the perspectival and mental aspect of reality. This mental aspect does not arise miraculously from the material aspect, rather it is 
IMPORTANT: When citing this article, please refer to the print-version:

\section{Honnefelder, Ludger / Runggaldier, Edmund / Schick, Benedikt (eds.) Unity and Time as Problems in Metaphysics. Berlin/New York: 2009, 237-252.}

a fundamental feature of reality (Stapp 2007). But without doubt, Leibniz' view goes considerably further; his idealism grounds all physical objects in mental states of the monads, thus rendering the physical world but a "well-founded phenomenon."

This idealistic reading of the absolute carrier problem seems unnecessary. It is not required to claim that all relational facts are mere phenomena. It would suffice to show that relational properties need to be completed and "filled" by absolutely intrinsic properties in order to gain a foothold in concrete reality. To distinguish this solution to the problem of ultimate realizers from Leibniz's idealism, one should characterize it as a dual aspect theory; the relational properties account for the structural form, but the absolutely intrinsic properties account for the ultimate realizers of the relational structure. One might even think of some kind of "hylomorphism" of the relational and the intrinsic. Both aspects together constitute a concrete natural individual. Thus the relational and the intrinsic aspects of reality have basic ontological status, without one having clear priority over the other. Alternatively, a neutral monism can also serve as the metaphysical framework. In this case, the basic properties of the world are neither physical nor phenomenal, but the phenomenal and the physical are constructed out of them. "From their intrinsic natures in combination, the phenomenal is constructed; and from their extrinsic relations, the physical is constructed" (Chalmers 1996, 156). But in any case, this ontology implies that perspectival representation is a fundamental feature of the world. Each natural individual has some representational perspective on the world. Mere conglomerates do not (as such) have this perspectival unity, only the simples that constitute them may again be unified in this way. The classic distinction between true substances and mere conglomerates can thus be explained in this metaphysical picture. Mental or proto-mental intrinsic properties can thus play an important role in solving the "special composition problem" for substances.

In recent philosophy of mind there has been a discussion whether consciousness is grounded in intentionality, or intentionality is grounded in consciousness. Reductive representationalists argue that phenomenal properties are equivalent to representational properties that can be completely characterized in non-phenomenal terms. If this is true, then built-in representational perspectives will not solve the absolute carrier problem because they are again merely structural. In order to solve the absolute carrier problem we need carriers that are absolutely intrinsic. Again, the only candidates for properties of this kind we know of are phenomenal, experiential mental properties. It is this fact which lends substantial support for some kind of panpsychism.

It was the purpose of this paper to show that this move is not only motivated by non-reductionist arguments in the philosophy of mind but equally by the argument for intrinsic natures in the metaphysics of concrete particulars. It is this mutual support of independently well-motivated reasons that makes the overall argument compelling. This complex edifice of metaphysical assertions does not come without a price, however. Thomas Nagel has famously remarked that "panpsychism has the faintly sickening odor of something put together in a metaphysical laboratory" (Nagel 1986, 49). The position is initially counter-intuitive, and only as a result of lengthy argumentation is it gaining some plausibility. There are, of course, "simpler" alternatives. Assuming so far unknown absolutely intrinsic properties of matter is certainly a possibility. Russell sometimes preferred skepticism: "The only legitimate attitude about the physical world seems to be one of complete agnosticism as regards all but its mathematical properties" (Russell 1927, 270). This sounds reasonable indeed, and a certain amount of skepticism with regard to absolutely intrinsic properties is well-advised. But that leaves us with a significant gap in our understanding. On the other hand, there remains the intuitive force of the genetic argument: "We ought ... to try every possible mode of conceiving of consciousness so that it may not appear equivalent to the 
IMPORTANT: When citing this article, please refer to the print-version:

Honnefelder, Ludger / Runggaldier, Edmund / Schick, Benedikt (eds.) Unity and Time as Problems in Metaphysics. Berlin/New York: 2009, 237-252.

irruption into the universe of a new nature non-existent to then" (James 1890, 148).

\section{$\underline{\text { References }}$}

- Adams, R. (2007) 'Idealism Vindicated' in: van Inwagen, P. and Zimmerman, D. (eds.), Persons. Human and Divine, Oxford: Oxford University Press, 35-54.

- Bohm, D. (1990) 'A New Theory of the Relationship of Mind and Matter', in: Philosophical Psychology 3, 271-286.

- Chalmers, D. (1996) The Conscious Mind. In Search of a Fundamental Theory, Oxford: Oxford University Press.

- Chalmers, D. (2002) 'Consciousness and its Place in Nature' in: Chalmers, D. (ed.), Philosophy of Mind, New York: Oxford University Press, 247-272.

- Chalmers, D. (2009) 'The Two-Dimensional Argument Against Materialism' in: McLaughlin, B., Beckermann, A., and Walter, S. (eds.), The Oxford Handbook of the Philosophy of Mind, Oxford: Oxford University Press, available at: http://consc.net/papers/2dargument.html.

- Descartes, R. (1644) Principles of Philosophy, Translation with Explanatory Notes (Synthese Historical Library) by Miller, R.P (1991), Dordrecht: Kluwer.

- Dipert, R. (1997) 'The mathematical structure of the world: the world as graph', in: Journal of Philosophy 94, 329-358.

- Eddington, A. (1920) Space, Time and Gravitation, Cambridge: Cambridge University Press.

- Haugeland, J. (1993) 'Pattern and Being' in: Dahlboom, B. (ed.), Dennett and His Critics, Cambridge: Blackwell, 53-69.

- Hume, D. (1739) A Treatise of Human Nature. New Edition. London: 1886.

- James, W (1890) The Principles of Psychology, vol. 1, New York: Henry Holt. Reprinted 1950: New York: Dover Publications.

- Nagel, T. (1979): 'Panpsychism' in: Nagel, T., Mortal Questions. Cambridge: Cambridge University Press, 181-195.

- Nagel, T. (1986) The View from Nowhere. Oxford: Oxford University Press.

- Newman, M. (1928) 'Mr. Russell's Causal Theory of Perception', in: Mind 37, 137-148.

- Putnam, H. (1980) 'Models and Reality', The Journal of Symbolic Logic 45, 464-482.

- Rosenberg, G. (2004) A Place for Consciousness. Probing the Deep Structure of the Natural World. Oxford: Oxford University Press.

- Russell, B. (1927) The Analysis of Matter. London: Routledge. 
IMPORTANT: When citing this article, please refer to the print-version:

Honnefelder, Ludger / Runggaldier, Edmund / Schick, Benedikt (eds.) Unity and Time as Problems in Metaphysics. Berlin/New York: 2009, 237-252.

- Russell, B. (1948) Human Knowledge. Its Scope and its Limits. London: Routledge.

- Seager, W (2006) 'Rosenberg, Reducibility and Consciousness', in: Psyche 12, 1-15.

- Stapp, H. (2007) Mindful Universe: Quantum Mechanics and the Participating Observer. New York: Springer.

- Strawson, G. (2006) 'Realistic Monism' in: Strawson, G. (ed.). Consciousness and its Place in Nature. Does Pbysicalism entail Panpsychism?, Exeter: Imprint Academic, 3-31.

- Whitehead, A. N. (1925) Science and the Modern World. Reprinted: New York 1997: Simon and Schuster. 